Arteterapia. Papeles de arteterapia y educación para inclusión social ISSN-e 1988-8309

https://dx.doi.org/10.5209/arte.65090

\title{
Proyecto: "Prevención en violencia de género dentro de la relación de pareja adolescente". Experiencia grupal con adolescentes del taller de artes con enfoque terapéutico
}

\author{
Deborah Valentina Muñoz Briones ${ }^{1}$
}

Recibido: 31 de octubre de 2018 / Aceptado: 11 de abril de 2019

Resumen. En el siguiente artículo describo la experiencia de un taller de artes desarrollado durante el primer periodo académico del año 2018, que tuvo como objetivo entregar herramientas para prevenir situaciones de violencia de género dentro de la relación de pareja adolescente. El taller contempló recursos propios del arteterapia y fue realizado en un establecimiento educacional que recibe subvención del Estado, cuya misión se centra en educar a los alumnos dentro de un proceso de formación integral, potenciando sus aprendizajes para lograr optar a una carrera universitaria. Los estudiantes que componen esta comunidad educativa son de un estrato social medio (clase media y media baja), varios de ellos provenientes de sectores rurales aledaños a la ciudad. El establecimiento está ubicado en la comuna de San Fernando, región de O'Higgins, Chile.

Primeramente se trabajaron actividades para reforzar los lazos de confianza entre los participantes; posteriormente se realizó una presentación sobre estereotipos de género y cómo estos se exhiben en el quehacer cotidiano. Luego se revisó qué es la violencia de género y cómo es posible identificar el cómo y por qué surge dentro de las relaciones de pareja adolescente. Finalmente, los participantes definieron lo que para ellos significa una relación de pareja estable, libre de situaciones de violencia.

La disciplina del arteterapia fue fundamental para trabajar los aspectos antes mencionados, pues permitió a los participantes comunicarse de forma visual e intuitiva; el inconsciente (concepto fundamental en arteterapia por proyectarse en la realización de imágenes) se manifestó a través del arte y facilitó procesos terapéuticos y creativos en los estudiantes, profundizando lo que corresponde a la violencia de género, su origen y consecuencias.

A continuación, describo lo observado durante las actividades realizadas en el taller: la interacción de los participantes en la realización de las consignas y sus preguntas y respuestas ante éstas, tanto de manera visual como oral. El grupo intervenido estuvo compuesto de 10 estudiantes que cursaban su último año de educación media (preparatoria), de género mixto. El taller duró todo un semestre y se realizó después de las horas de clases habituales, una vez por semana en la sala de artes del mismo establecimiento, los materiales fueron dados a los participantes en cada sesión y su duración fue de 1:30 hrs. (con un total de trece sesiones).

Palabras claves: Adolescencia, autoestima, estereotipos de género, violencia de género, arteterapia.

\section{[en] Project: Preventing gender-based violence in adolescent relationships. Group experience with adolescents in Art Workshop with therapeutic focus}

Abstract. In the following article, I will describe the experience of an Art Workshop developed during
the first academic period of 2018, which aimed to provide tools to prevent situations of gender-based
violence within adolescent romantic relationships. The workshop included resources from art therapy
and was carried out in an educational institution that receives a grant from the Chilean State. This
institution's mission is to educate students within a process of integral formation, enhancing their

1 Pontificia Universidad Católica de Chile

E-mail: dvmunoz.neo@gmail.com 
learning to have the possibility to go to University. The students from this educational community are from middle and lower middle class. Several students come from rural sectors close to the city where the school is located, that is, San Fernando, Chile.

First, activities were carried out to strengthen the bonds of trust between the participants. Subsequently, a presentation was made on gender stereotypes and how these are exhibited in daily life. Then, we reviewed what gender-based violence is and how it is possible to identify how and why it arises within the romantic relationships of adolescents. Finally, the participants defined what a stable relationship meant to them, that is, free from violent situations.

The discipline of art therapy was fundamental to work on the aspects just mentioned since it allowed participants to communicate visually and intuitively. The unconscious (a central concept in art therapy because it is projected in the creation of images) was manifested through art and facilitated therapeutic and creative processes in the students, deepening what gender-based violence means, as well as its origin and consequences.

In this article, I will describe my observations of the activities carried out in the workshop; the interaction of the participants in the realization of the instructions, also their questions and answers before them, both visually and orally. The intervened group consisted of 10 students who were in their last year of secondary education (high school), of mixed gender. The workshop lasted a whole semester and was held after the usual School classes, once a week at the School's art classroom. The materials used were provided by the School to the students in each session, which lasted 1,5 hours (with a total of thirteen sessions).

Keywords: Adolescence; self-esteem; gender stereotypes; gender-based violence; art therapy.

Sumario. 1. Introducción. 2 Fundamentación ¿Por qué Arteterapia? 3. Descripción Taller. 4. Conclusión. 5. Referencias.

Cómo citar: Muñoz Briones, D. V. Proyecto: “prevención en violencia de género dentro de la relación de pareja adolescente". Experiencia grupal con adolescentes del taller de artes con enfoque terapéutico, en Arteterapia. Papeles de arteterapia y educación para inclusión social 14, 2019, 97-111.

\section{Introducción}

Durante este año (2018) los medios de comunicación han difundido cómo la violencia de género contra las mujeres ha cobrado un alarmante número de víctimas en Chile. A la fecha (septiembre 2018), se han perpetrado 38 femicidios (Femicidios 2018 - Red Chilena contra la Violencia hacia las Mujeres, 2018) en donde el 10,5\% corresponde a mujeres en edad adolescente (rango de los 12 a los 19 años).

La Red Chilena Contra la Violencia Hacia las Mujeres es un grupo surgido en los años ' 90 cuyo enfoque ha estado persistentemente en erradicar todas las formas de violencia hacia las mujeres, realizando campañas, movilizaciones, intervenciones en el espacio público, etc. Este grupo realiza año a año un seguimiento de las mujeres que han sido asesinadas por motivos de género. En su listado incluyen a víctimas que han sido asesinadas por sujetos que no necesariamente han tenido un vínculo íntimo con aquellas, esto se denomina feminicidio, concepto acuñado por la académica mexicana Marcela Lagarde, el cual contempla el asesinato de mujeres por el hecho de ser mujeres (Lagarde, 2006). Esto implica directamente que las cifras de mujeres asesinadas anualmente manejadas por la Red Chilena son mayores a las presentadas por el Gobierno Chileno, a través del Ministerio de la Mujer y la Equidad de Género (2018), quienes definen femicidio como "(...) el asesinato de una mujer realizado por quien es o ha sido su esposo o conviviente".

La violencia de género es transversal, tanto mujeres como hombres pueden llegar a ser víctimas de violencia por parte de sus parejas, pero el número de mujeres víctimas es mayor y, a su vez más visibilizado que en el caso de los hombres, quienes 
generalmente no denuncian estos hechos, haciendo más difícil su exposición: “(...) al no existir una institución exclusiva para varones, estos no denuncian" (Fontena \& Gatica, s.f.). Cabe indicar que en el discurso feminista generalmente se describe al hombre como ente violento, señalando " $(. .$.$) a un solo tipo de agresor: al varón,$ manteniendo oculta esta problemática [de hombres víctimas de violencia doméstica]" (Fontena \& Gatica, s.f.). Esta situación hace evidente la necesidad de educar a toda la comunidad y entregar herramientas para evitar situaciones violentas en las relaciones de pareja.

En las dinámicas creadas para combatir la violencia doméstica, es importante que la participación de los varones sea inclusiva, evitando mensajes culpabilizadores (Vizcarra, Poo \& Donoso, 2013), para que así desarrollen la habilidad de la empatía.

A raíz de las preocupantes cifras de asesinatos de mujeres por motivos de género, como docente comencé a reflexionar sobre qué es lo que no estamos haciendo bien como sociedad. Asimismo, me percaté y preocupé de la necesidad de educar al estudiantado sobre temas atingentes a ellos, particularmente vinculados con las relaciones de pareja, donde resulta fundamental conocer las consecuencias de participar de una relación insana e identificar y tener las herramientas para prevenir situaciones violentas. Por este motivo, consideré importante otorgar espacios de reflexión dentro de las aulas y debatir sobre estos temas, cómo actuamos como sociedad ante hechos de violencia. Es necesario reflexionar sobre estas situaciones en conjunto con los adolescentes, presentándolas de manera didáctica, motivadora y enriquecedora, para así convertir la discusión en una experiencia significativa. Fue así como llegué a la conclusión de realizar un taller de artes que tuviese un enfoque terapéutico, dirigido a estudiantes en edad adolescente. El objetivo principal fue educar a los participantes para así prevenir situaciones de violencia de género dentro de la relación de pareja.

\section{Fundamentación: ¿Por qué arteterapia?}

Al momento de diseñar el proyecto (trabajo grupal que realicé en conjunto con dos psicólogas), se consideró que el arteterapia puede resultar fundamental para abordar las emociones y los conflictos internos de los estudiantes, pues " (...) facilita la expresión y la reflexión, además es de gran ayuda cuando el funcionamiento normal del individuo se ve alterado, ya sea por razones biológicas, psíquicas o sociales" (Marxen, 2011, p. 13). El arte, como tal, es intrínsecamente terapéutico, pues “(...) puede ser una herramienta. Lo que debemos hacer es definir exactamente qué clase de herramienta es y qué nos puede aportar" (Botton \& Armstrong, 2017, p. 4). Al utilizar el arte como herramienta, es posible desarrollar un lenguaje visual que nos permite comunicarnos cuando las palabras faltan, por lo tanto, se deja a un lado el carácter estético del arte y se da énfasis a la creación. En este caso, es importante poner el foco en el proceso del hacer arte más que su resultado, pues "(...) en el caso de la terapia, lo más importante de todo es la persona y el proceso, dado que el arte se utiliza como medio de comunicación no verbal" (Dalley, 1987, p. 15). En el momento en que los sujetos no son capaces de verbalizar sus conflictos internos es cuando el arteterapia surge como una gran alternativa, pues permite canalizar de forma visual estos conflictos: “(...) la creación artística es una forma de explorar nuestra imaginación y empezar a permitirle ser más flexible, aprender a ver más opciones" (Allen, 2017, p. 20). 
En relación con otro punto primordial de este artículo, la violencia en el noviazgo se define como:

Cualquier acción o conducta que cause daño físico, psicológico o sexual dentro de una relación de pololeo, noviazgo o cualquier tipo de relación amorosa, en este caso, entre los jóvenes. Esta situación tiene consecuencias nefastas para la víctima, su entorno y para la sociedad en general. (¿Qué es la violencia en el pololeo? - Pololeo Sin Violencia, 2017)

La violencia dentro de la relación de pareja produce emociones de carácter negativo, siendo el miedo, inseguridad, vergüenza, vulnerabilidad e indefensión lo que ocasiona disminución en la autoconfianza y autoestima de quien la padece (Zolezzi, 2013). Por lo tanto, es fundamental que los sujetos posean una autoestima equilibrada y positiva para no ser vulnerados en relaciones de pareja con señales de violencia.

El taller de artes realizado se enfocó en lo preventivo, entregando a los estudiantes -a través de ejercicios de arteterapia- herramientas necesarias para consolidar y reforzar su autoestima:

Un niño con baja autoestima no confía en sí mismo y tampoco confía en los demás. Suele ser inhibido, crítico, poco creativo o, como conducta compensatoria, suele desarrollar una tendencia a menospreciar los logros de los demás, así como a tener conductas agresivas o desafiantes. Con esto, a su vez, es rechazado por los otros. Así, cuanto menos valora a los demás es, a su vez, menos valorado por el mundo externo. (Haeussler \& Milicic, s.f., p.15)

Como profesora que trabaja con adolescentes consideré fundamental identificar a aquellos estudiantes con baja autoestima y poca seguridad en sí mismos, para invitarlos a reforzar en el taller este aspecto fundamental en su desarrollo físico y emocional. En este sentido, es importante consolidar la seguridad y aceptación personal de los adolescentes, con el objetivo de formar adultos sólidos, seguros de sí mismos y de aceptar su realidad tal cual es, tolerantes y respetuosos, capaces de canalizar su agresividad a través del arte.

Finalmente, los estereotipos de género insertos en nuestra cultura definen al sujeto sobre la base de su condición física-biológica (mujer-hombre) y estos dan pie a que los individuos entren en un rol condicionado, normalizando conductas de carácter violento del sujeto activo (hombre) sobre el pasivo (mujer). Por lo tanto, al trabajar con recursos del arteterapia podemos lograr que los estudiantes identifiquen y reflexionen sobre el significado de cada uno de estos estereotipos:

(...) la mujer casi siempre suele ser el objeto (pasivo) de la mirada masculina, frente a la posición de sujeto (activo) del hombre. Femenino se ha relacionado durante mucho tiempo -y aún sigue haciéndose con pasividad, debilidad, objeto sexual...Hay que rechazar todos estos modelos y crear otros alternativos. (Alonso, 2004, p.263) 
Los estereotipos de género no dan libertad de expresión a los individuos con respecto a cómo se sienten e identifican. En este sentido, la identidad de la persona pasa a un segundo plano, ya que los estereotipos coartan al sujeto a ser lo que dictan las normas sociales. Estos modelos se deben replantear, para así lograr construir una sociedad mas equitativa. Trabajar las estrategias del arteterapia con adolescentes permite darles libertad de expresión la posibilidad de reflexionar desde el arte de manera profunda sobre quiénes son y quiénes quieren ser.

\section{Descripción Taller}

Primeramente, expuse al director del establecimiento el programa y la descripción del taller, en donde mencioné los objetivos y las sesiones a trabajar, lo cual fue aprobado para su ejecución desde este año (2018) como taller extraprogramático, es decir, después de las clases habituales. Elegí comenzar con $4^{\circ}$ medio (último año de preparatoria), pues estaban prontos a egresar, para después realizarse con el resto de los cursos (enseñanza media, que comprende a estudiantes de 15 a 18 años). Los estudiantes que participaron de la primera versión del taller fueron identificados y seleccionados de acuerdo con las siguientes características: tener gusto por las artes, ser un grupo heterogéneo en cuanto a género, con experiencia en relaciones de pareja (sin ser excluyente) y que hubiesen sido víctimas de violencia (en algunos casos). Esta selección la pude llevar a cabo desde la observación que me permite mi rol de docente de artes visuales, cargo que ejerzo en dicho establecimiento. A su vez, consideré la opinión de los miembros del Departamento de Convivencia Escolar, compuesto por la orientadora y el psicólogo del establecimiento, teniendo en cuenta los informes de personalidad realizados por el mismo departamento. Asimismo, consideré la opinión de la profesora jefe, por ser quien conoce mejor el núcleo familiar de los estudiantes.

La participación de los estudiantes en el taller no fue obligatoria, pero sí se les recalcó lo importante de su asistencia a cada sesión. Se seleccionaron ocho estudiantes como máximo, algunos fueron constantes y otros faltaron de vez en cuando, justificando su ausencia generalmente por tener responsabilidades académicas.

En la mayoría de las sesiones se optó por trabajar con la técnica del collage, pues “(...) reduce el miedo a tener que realizar imágenes estéticamente bellas” (Marxen, 2011, p. 65).

Al inicio del taller se les explicó a los estudiantes que en este espacio es más importante el lenguaje expresivo de las obras que su resultado estético; el arte es un medio que permite comunicar lo que está en nuestro interior, nuestras emociones. También se les recalcó constantemente durante las sesiones que ellos y ellas eran libres de decidir cuándo y cuánto comentar o de mantenerse en silencio con respecto a su experiencia con los ejercicios de arteterapia.

Como introducción al taller se expuso a los estudiantes de forma general en qué consiste la violencia de género, también se les indicó de manera más específica qué es el arteterapia; del mismo modo, se les recalcó lo importante de su compromiso con asistir a las sesiones de trabajo.

En el taller de artes se trabajó la autonomía desde la primera sesión en forma transversal, lo que a su vez permitió reforzar el autoestima, pues en cada sesión los 
estudiantes tuvieron que interpretar por sí mismos las consignas dadas. En un inicio, los participantes realizaron preguntas sobre cómo seguir adelante con su trabajo visual; en este espacio se les indicó que ellos debían hacerse cargo de sus decisiones sin involucrar a nadie dentro de su proceso creativo, ya que el yo interno se comunicaría a través de la interpretación de las consignas.

En la primera sesión los estudiantes fueron más contemplativos que activos, siguieron las instrucciones, pero con cautela; trabajaron en actividades de confianza y seguridad entre ellos. De esta manera, se construyó el encuadre del taller de forma colaborativa, que contempló el respeto, la empatía y la confidencialidad.

Se inició la sesión con dinámicas de conocimiento y confianza, en donde construyeron una carta de presentación sobre sí mismos a partir de la técnica del collage, destacando sus gustos y fortalezas. Esta actividad permitió que pudieran presentarse y conocer al resto de sus compañeros.

En la segunda sesión se visualizó mayor confianza en los estudiantes. Realicé preguntas con relación a sus trabajos, ellos tuvieron la libertad de decir lo que quisieran, si tenían confianza para abrir su intimidad al resto; si sentían que se exponían demasiado, se les mencionó que lo hicieran con cautela, la idea era construir un espacio en el cual los participantes se sintieran cómodos de compartir sus experiencias.

Comenzaron la sesión realizando un ejercicio pictórico fluido, que consistió en trabajar de forma libre con pinturas; en este caso utilizaron témperas y como soporte un trozo de papel hilado. Los estudiantes trabajaron en silencio, componiendo e interpretando la consigna: cómo me siento hoy. Ya terminada esta parte de la sesión, se observó que los participantes tenían miedo de empezar a compartir sus respuestas. Cuando finalmente comenzaron a exponer, algunos dijeron abiertamente lo que les pasaba o cómo se sentían, otros miraron en silencio y luego mencionaron algo muy breve, sin mayor detalle, Generalmente dijeron sentirse tristes, agotados, estresados, también rescataron que el ejercicio (pictórico fluido) los calmó, los hizo concentrarse y no pensar sobre lo que les hizo sentir mal minutos atrás. Finalmente, se les indicó que mencionaran un concepto que representase lo elaborado dando un título a la obra.

Luego pasamos al desarrollo de la sesión, en donde elaboraron un ejercicio de manera grupal respondiendo a la consigna: mi hogar y el espacio en común. El ejercicio consistió en representar la consigna en un gran trozo de papel, el cual fue intervenido por los estudiantes con lápices pastel, de forma grupal, decidiendo por sí mismos donde ubicar su hogar y dónde definir el espacio común de todos. En esta ocasión se relajaron más, se rieron e incluyeron el establecimiento por petición de una estudiante, mencionando que todos se conocen a través de éste, me incluyeron como su docente y también agregaron a algunos funcionarios sobre los cuales dijeron sentir afecto. Algunos estudiantes fueron más proactivos en participar, delineando y definiendo su espacio, otros hicieron su parte del hogar de forma más cauta. Finalmente, comenzamos a hablar sobre lo representado y cómo fue realizado el espacio en común (ver imagen 1).

Algunas representaciones del hogar fueron hechas de forma figurativa, otras abstractas, algunos dejaron su espacio abierto, otros cerrado. Luego, cada uno mencionó cómo interpretó la consigna, algunos entendieron el hogar como su casa física, otros como su núcleo familiar. Uno de los participantes -el que presentó mayor confianza en exponerse al resto- mencionó que en su hogar no se sentía 
afín, que no lo comprendían ni escuchaban, que solo quería crecer para poder salir de ahí y vivir su vida en paz, sin prejuicios. Este participante en particular vivía su homosexualidad de forma abierta, pero aún así se sentía afectado por el recibimiento de su familia y de algunos de sus compañeros. Los demás estudiantes opinaron al respecto, pero con cautela. En general, se observó que este grupo fue bien pasivo al momento de dar su opinión sobre lo que los otros comunicaban. Otros estudiantes en cambio, mencionaron sentirse cómodos con su hogar, que a pesar de haber peleas dentro de éste, eran sólo discusiones y que se sentían acogidos dentro de su núcleo familiar.

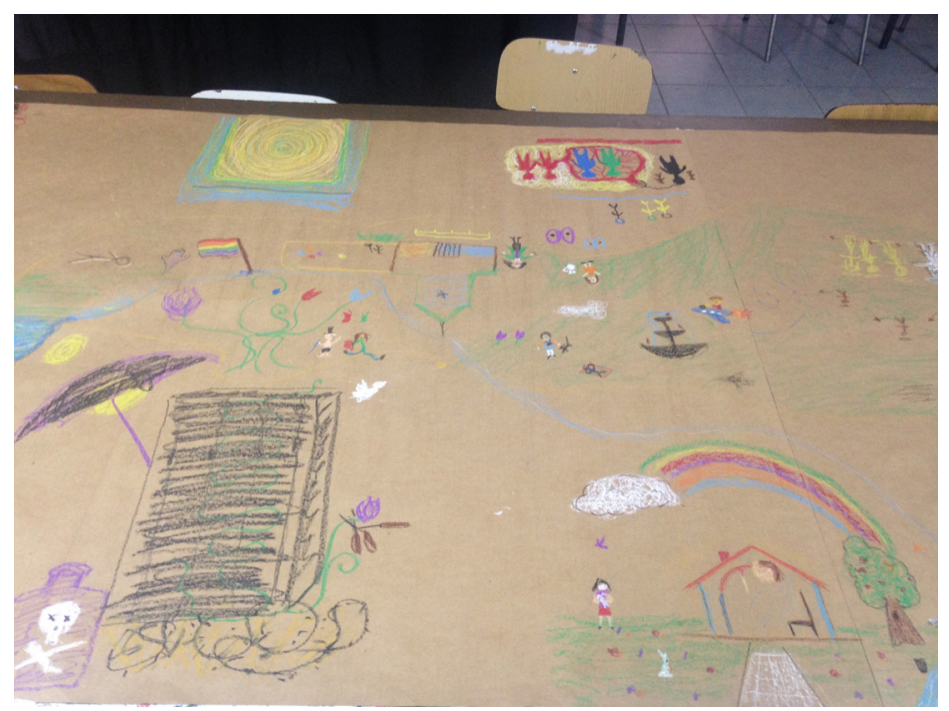

Imagen 1. Parte de la representación de la consigna: Mi hogar y el espacio en común.

Ya en la cuarta sesión los estudiantes comenzaron la clase caminando por la sala de forma libre, luego se saludaron con una parte del cuerpo diferente de la del saludo común (en Chile, se suele estrechar las manos o dar un beso en la mejilla), es decir, tocándose con la cabeza, el hombro, la rodilla, etc. Los estudiantes tomaron con humor la actividad y les permitió que se relajaran, lo cual generó un espacio de confianza, también yo intervine en la dinámica, lo que les causó más risa. Luego, fuimos al desarrollo de la sesión en donde les planteé preguntas sobre estereotipos de género. Se juntaron en parejas mixtas y discutieron sus respuestas en voz baja. Después, comenzaron a realizar un mapa corporal, en donde uno de los estudiantes se situó en el suelo sobre un pliego de papel craft y su compañero marcó su contorno corporal. Luego, el compañero del suelo se levantó e hizo lo mismo con el otro estudiante. Finalmente, cada uno se situó frente a su mapa corporal y respondió las preguntas planteadas inicialmente, interviniendo el mapa de forma visual. Esto fue realizado de forma respetuosa, en silencio, en plena concentración. Ya finalizada esta parte, cada estudiante comentó qué representó en el mapa corporal (imagen 2); se dio un espacio de reflexión en torno a la identidad, estereotipos de género, qué somos realmente y qué nos limita como mujer/hombre, según la sociedad. 


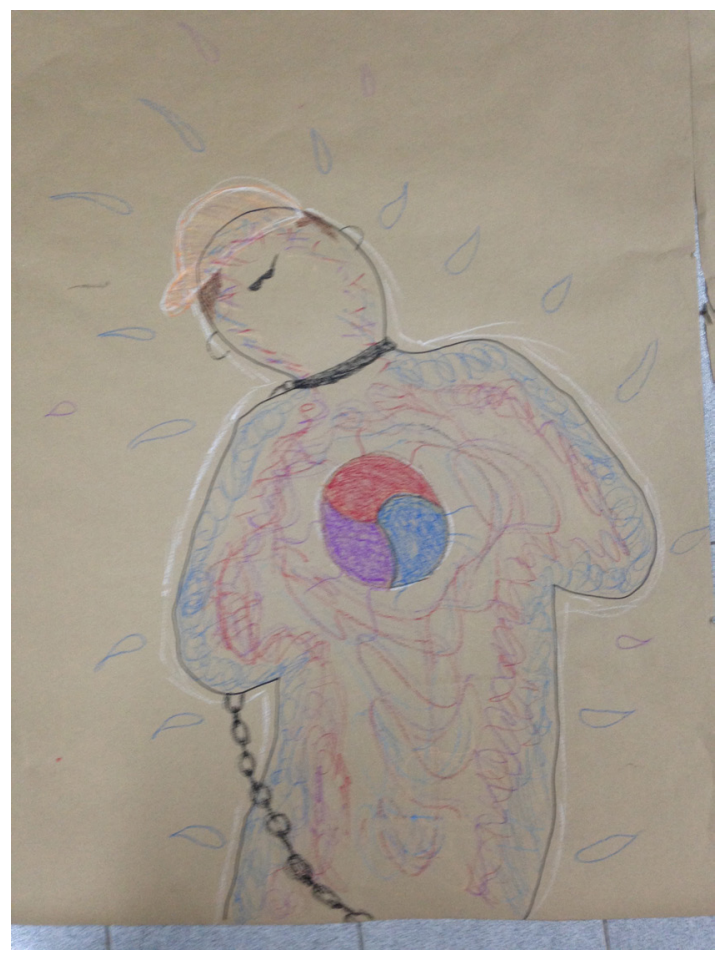

Imagen 2. Detalle mapa corporal.

Fue bastante enriquecedora la sesión en cuanto a respeto y confianza. Cada uno desde su punto de vista comentó sobre lo que es ser hombre, ser mujer, si les gustaba o no ser mujer/hombre. En el caso de las mujeres, varias mencionaron que no les gustaba la menstruación, por ser muy dolorosa e incómoda; por otra parte, expresaron que sí les gustaba poseer la facultad de procrear (independiente de llegar a ser madres o no), expusieron que esto hacía a las mujeres entes maravillosas, capaces de traer vida a este mundo. En el caso de los hombres, algunos manifestaron sentirse cómodos en su rol de hombres, porque sentían y se daban cuenta de que hay más libertades para ellos que para ellas. Uno de esos estudiantes mencionó que a veces se sentía discriminado por su propio grupo de amigos, por ejemplo, al no ser integrado en las conversaciones sobre fútbol, porque a pesar de practicar el deporte no lo veía en la televisión. Luego de la conversación general, un estudiante destacó en los últimos trabajos de uno de sus compañeros un lenguaje propiamente artístico de carácter expresionista. El autor de los trabajos indicó estar de acuerdo y dijo sentirse feliz, porque no se había dado cuenta de su potencial creativo, su compañero fue quien lo incentivó y orientó a darse cuenta de su forma de expresión visual.

En la quinta sesión, los estudiantes observaron una pieza de material audiovisual realizado por Fundación Honra (que trabaja por la equidad de género y la no violencia en las parejas), la cual en conjunto con la PDI (Policía de Investigaciones de Chile) realizan campañas para prevenir la violencia en el noviazgo. El material audiovisual mostró elementos propios de la violencia de género en diversas circunstancias, estos incluían violencia ejercida tanto por hombres como mujeres, 
representados a partir de ilustraciones y breves diálogos. Luego de que vieran el video les di espacio para que compartieran su opinión con respecto al material mostrado. Les pregunté si conocían la fundación, si estaban familiarizados con los elementos que constituyen violencia de género, si habían vivido u observado alguna situación como las presentadas. En esta oportunidad, comentó solo una estudiante preguntando qué pasaba cuando estas situaciones ocurrían con alguna amistad. A continuación, reflexionamos en conjunto en torno a lo expuesto y sobre lo importante que es el respeto, la confianza, la empatía y la asertividad. En grupo, concluimos que ningún tipo de relación debía contener elementos de violencia.

Luego de esta reflexión, los estudiantes construyeron un afiche representando lo siguiente: ¿cómo sería una relación de pareja sin elementos de violencia de género? Para ello, utilizaron diversos materiales, cada uno tuvo la autonomía para decidir con qué realizar su afiche. En general, se visualizó de buen ánimo al grupo, no se observó a algún estudiante incómodo con la actividad, ya que todos trabajaron de forma concentrada. En un inicio comenzaron a realizar la consigna algo inquietos, desordenados, pero pronto se fueron calmando y realizaron el afiche en silencio. Al finalizar, costó que los estudiantes de forma voluntaria comenzaran a hablar sobre lo que significaba su trabajo.

A raíz de lo expuesto, todos concordaron qué conceptos eran importantes dentro de una relación sana: amor, confianza, respeto, seguridad, libertad y espacio personal. Solo una estudiante no quiso compartir lo que significaba su afiche, estaba cabizbaja luego de realizar el trabajo. Para no intimidarla, solo se le solicitó que dijera en una palabra lo que había aprendido.

En la sexta sesión comenzamos con una dinámica de identificación de gustos y preferencias. Para ello, todos caminaron de forma libre en la sala, la mayoría estaba dispuesta a realizar la actividad y estaban de buen ánimo, bromeando y riendo. Luego, les pedí que se sentaran alrededor de un gran mesón. En el centro, dispuse hojas de revistas con avisos publicitarios de todo tipo de productos y servicios. Solicité a los estudiantes escoger una imagen que les hubiese llamado la atención. Después, les pregunté el porqué de su decisión; ante esto, la mayoría de los estudiantes se refirieron a la estética, describiendo los colores, el producto, el/la modelo. Una estudiante logró ver más allá, se dio cuenta de que la imagen que escogió mostraba estereotipos de género y expuso de qué manera se presentaban en la publicidad. Todos sus compañeros observaron sus imágenes nuevamente, pero con una perspectiva distinta y se dieron cuenta de los estereotipos de género presentes en ellas, más aún, cómo estos aparecen generalmente en la publicidad.

Luego, los estudiantes intervinieron las imágenes previamente escogidas a partir de la técnica del collage, el objetivo fue recrearlas dejando de lado los estereotipos de género (imagen 3). Les pedí que trabajaran en silencio; todos se veían concentrados en la actividad. Ya finalizada esta parte, los estudiantes presentaron las modificaciones hechas y comentaron qué fue lo que quisieron expresar. Algunos seguían recurriendo a los estereotipos de género al exponer sus impresiones y en el lenguaje visual utilizado. Lo positivo fue que un estudiante se dio cuenta e indicó la situación a sus compañeros. De esta manera, se logró el objetivo con respecto a desarrollar la autonomía, ya que hubo un aprendizaje y reflexión en torno a los estereotipos que hay en la publicidad y que están presentes en nuestra cotidianeidad. 


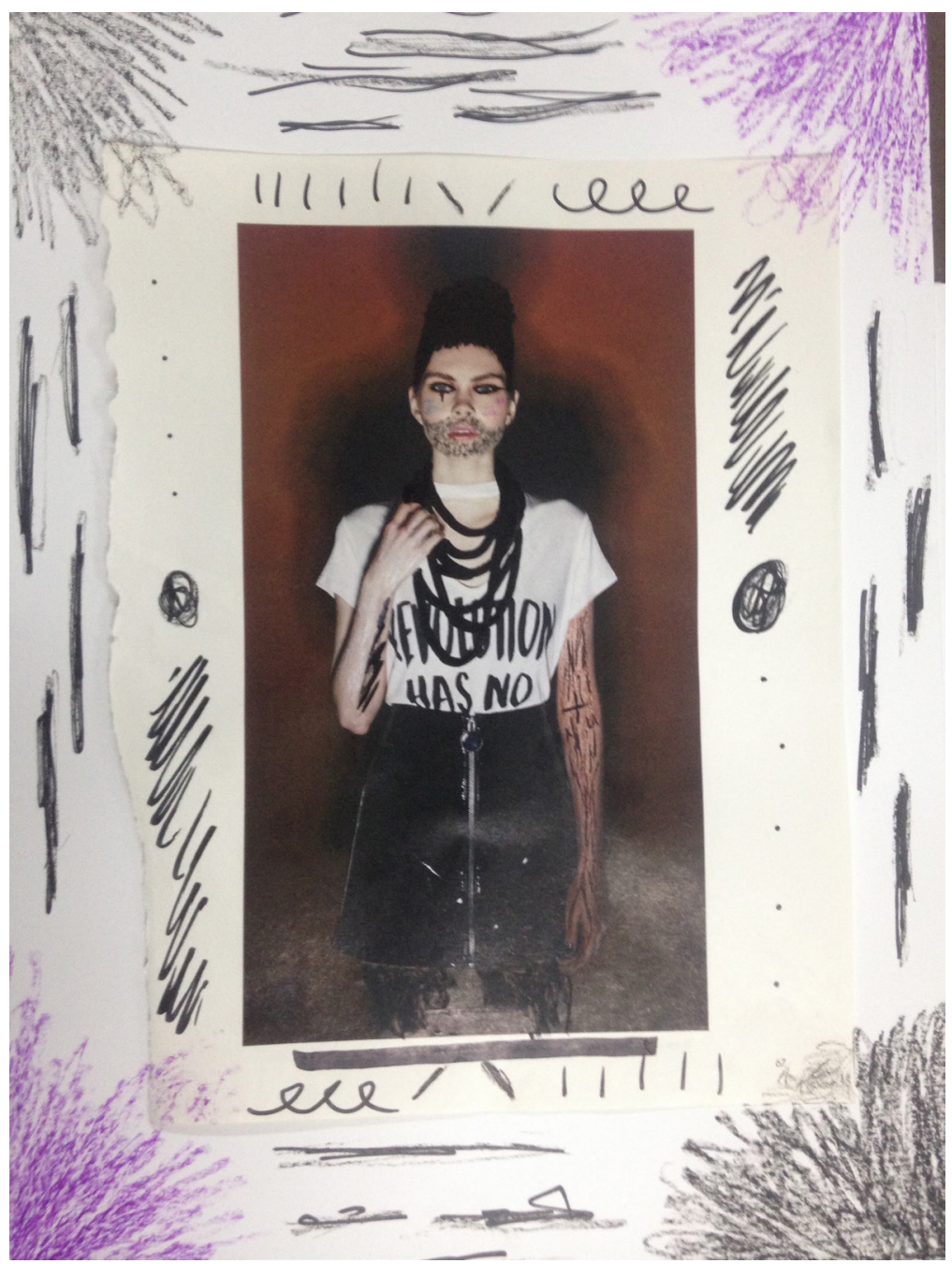

Imagen 3. Propuesta de publicidad sin estereotipos de género.

Ya en la novena sesión, los estudiantes respondieron a la pregunta ¿cómo se han sentido en el transcurso del taller? En un inicio, costó que expresaran lo que les pasaba, se quedaron en silencio esperando que alguno de sus compañeros comenzara a hablar. Lentamente comentaron sus experiencias sobre la consigna. La mayoría de los participantes mencionó sentirse estresado, agregando que el espacio del taller les permitía hacer un alto en cuanto sus preocupaciones y responsabilidades diarias. Posteriormente, participaron en el desarrollo de la sesión, que consistió en representar la personificación de su pareja o cómo les gustaría que fuese su pareja. Para ello, les pedí que utilizaran la técnica de la fotografía (con sus teléfonos móviles), la cual permitió que pudieran ver resultados más inmediatos. A gran parte del grupo le gustó trabajar con fotografía en el taller, por considerarla un medio que utilizan para comunicarse diariamente, rápida, cómoda y familiar, que permite editar y corregir elementos visuales de forma inmediata. 

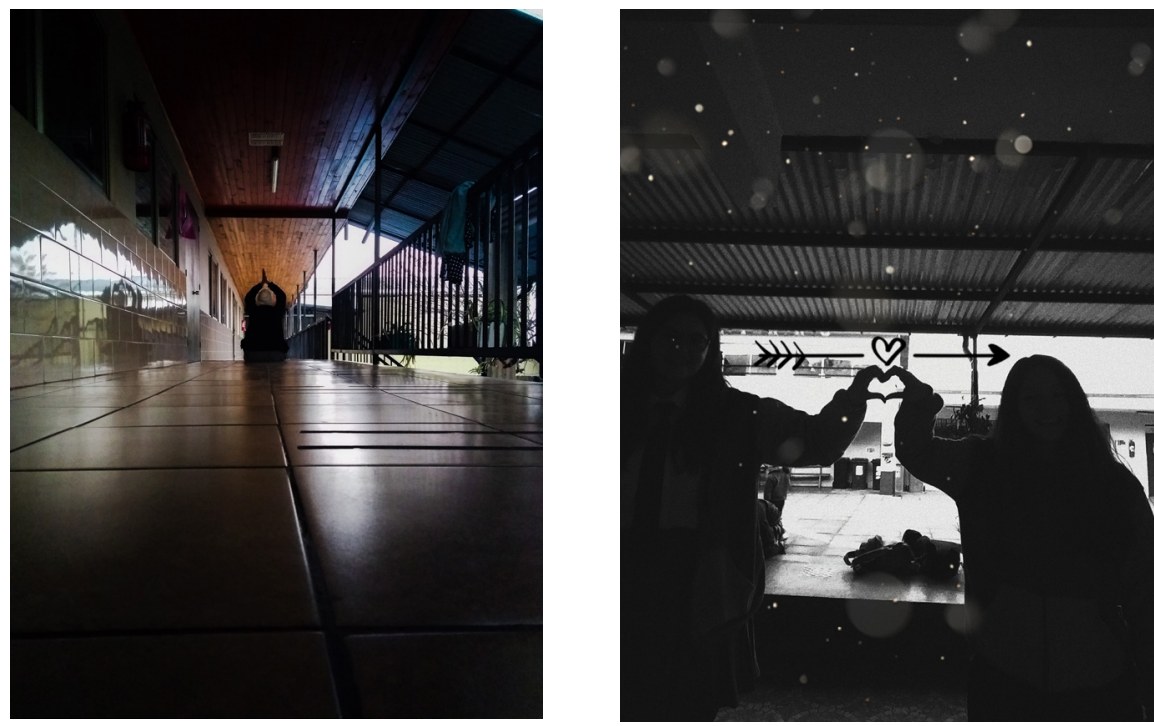

Imagen 4 y 5. Representación consigna: personificación de su pareja o cómo le gustaría que fuese su relación de pareja.

A través del ejercicio anterior los estudiantes destacaron, en general, que las características de una buena relación serían: apoyar, amar, cuidar y respetar sin menoscabar al otro, dando la libertad de hacer cosas tanto juntos como individualmente. Basaron esta respuesta en la reflexión de que una sana relación de pareja no debía contener elementos estereotipados. Una estudiante manifestó que en su anterior relación de pareja ocurrieron situaciones de violencia de género y que a través de este taller pudo identificar dichas situaciones, logrando también definir qué quería en su próxima relación.

En la sesión número once los estudiantes se sentaron en sus sillas y les indiqué la postura que debían tener, cómoda, pero sin llegar a quedarse dormidos. Les pedí que cerraran los ojos y escucharan el audio de una meditación tipo consciente (mindfulness), enfocada en que se conectaran con su cuerpo y se concentraran en la respiración. Después de realizado el ejercicio, les pregunté qué les había parecido, si lo habían hecho antes, si lo conocían. Todos manifestaron que nunca habían meditado y que les resultó difícil concentrarse, ya que tenían diversos pensamientos en la mente. Aun así, lo disfrutaron mucho, indicaron que había sido un momento necesario para ese día tan agitado.

Posteriormente, pasaron a responder la siguiente pregunta: ¿qué ha sido lo más significativo para ti sobre los contenidos vistos en el taller? Gran parte de los estudiantes respondieron que lo que más les llamó la atención fue el ejercicio de meditación consciente, les permitió que se conocieran más a sí mismos escuchando su cuerpo y su respiración. También comentaron que a través del taller habían logrado conocer su mundo interno y a sus compañeros, más allá de la idea preconcebida que antes tenían; asimismo, habían podido escuchar y escucharse.

Luego, comenzaron a trabajar en una estructura de libro de artista denominada encuadernado tipo acordeón. Para ello, siguieron las instrucciones que les indiqué sobre cómo realizarla. Cuando estuvieron listas las estructuras de sus libros, los es- 
tudiantes respondieron de forma visual: ¿cómo puedo vivir una relación de pareja sin elementos de violencia de género?

En un principio resultó complejo lograr que trabajaran de forma autónoma, me preguntaban de qué manera podían representar la consigna, ante lo cual les indiqué que debían interpretarla de forma libre, utilizando los materiales dispuestos para ello (papeles de colores, lápices de colores, recortes de revistas, fotografías impresas, pegamento). La construcción del libro tomó dos sesiones del taller.

Finalmente, en la última sesión (número trece), los estudiantes debieron mencionar a partir de su saludo qué dejaban y qué se llevaban de lo experimentado. Esto les resultó difícil en un principio y les tomó un tiempo contestar la pregunta. Dijeron sentirse un poco tristes, porque el taller se terminaba, que este espacio les había entregado un momento de calma y reflexión sobre sí mismos. Luego, presentaron el libro de artista que habían confeccionado en la sesión anterior.

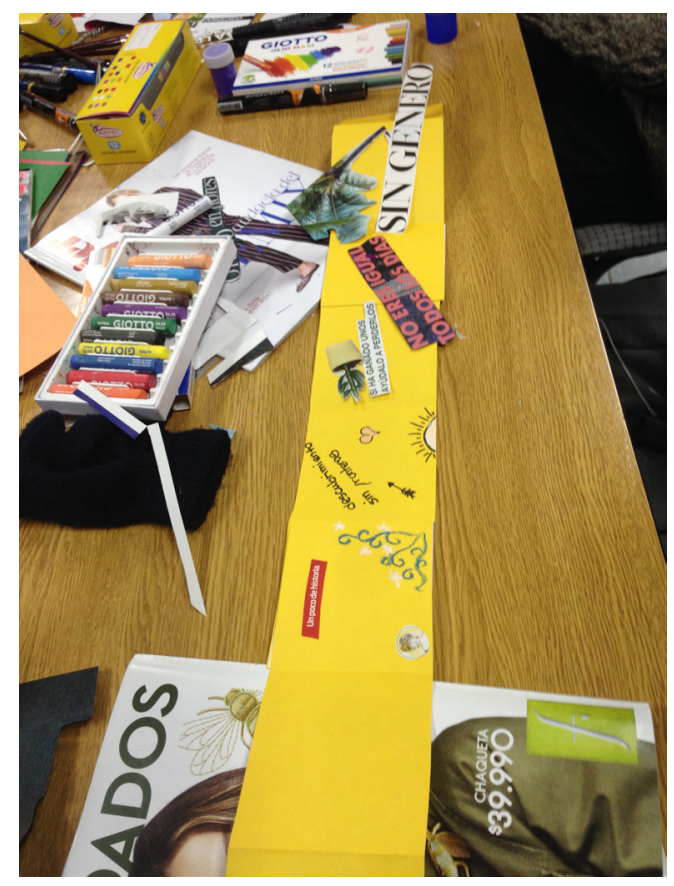

Imagen 6. Construcción de libros de artista tipo acordeón.

Compartieron su libro y mencionaron qué les pareció realizarlo. Algunos manifestaron que fue frustrante el resultado técnico, otros se dejaron llevar y plasmaron lo que les venía a la mente. Se visualizó inseguridad con relación a lo estético, aun cuando se trataba de la última sesión y en repetidas ocasiones se les dijo que lo importante de las obras era su poder comunicativo. En general, los estudiantes expusieron en sus libros los conceptos que para ellos eran fundamentales a la hora de estar en una relación de pareja sin elementos de violencia de género: respeto, amor, empatía, confianza, libertad y honestidad, todo esto construido desde la intervención de imágenes, dibujos y pintura.

Por último, a modo de cierre, realizaron un autorretrato estilo selfie que representara la emoción que sentían por el cierre del taller. Conversamos sobre el resultado 
final y la mayoría dijo sentirse triste, lamentando que este espacio ya no siguiera, agregando que les sirvió para poder expresarse sin juicios externos y pensar en sí mismos.

\section{Conclusión}

Se supone que el amor es una parte placentera de la vida, pero no hay nadie a quien podamos hacer más daño, o que pueda hacérnoslo a nosotros, que aquellos con quienes tenemos una relación (...) esperamos que el amor sea fuente de satisfacción, pero a veces se convierte en territorio de descuidos, deseos no correspondidos, venganza y abandono. (Botton \& Armstrong, 2017, p. 94).

El concepto del amor ha sido recreado en nuestra cultura, a través de imágenes y de costumbres que heredamos de quienes nos educaron y que fueron parte de nuestra crianza. En nuestra infancia vemos demostraciones de afecto en otras personas, las conductas las vamos repitiendo y así nos educamos sobre cómo ser pareja o cómo estar en una relación de pareja. No obstante, cuando estos modelos de referencia son de carácter violento se convierten en un problema, pues se puede llegar a normalizar esta conducta.

Este es uno de los motivos por los que consideré importante educar a los estudiantes en edad adolescente sobre cómo vivir una relación de pareja saludable, libre de violencia de género. De esta manera, el taller desarrollado se convirtió en un aporte a la formación integral de los participantes, pues les entregó herramientas para identificar y prevenir situaciones de violencia.

Aun así, considero que en el futuro será necesario potenciar aún más la comprensión sobre qué son los estereotipos de género, ya que hasta la última sesión del taller algunos estudiantes continuaron incluyendo frases que representaban ciertos estereotipos. A pesar de que el aprendizaje sobre estos temas es un proceso lento, pues vivimos rodeados de mensajes que encasillan a hombres y mujeres en ciertos roles, he podido concluir que profundizar más en el significado de los estereotipos podría resultar beneficioso para la comprensión de los estudiantes.

Como docente de artes, la experiencia de realizar el taller fue fructífera, pues me permitió conocer parte de la realidad que viven los adolescentes, sus inquietudes, sus inseguridades, sus miedos, su forma de ver el amor y cómo éste debería ser en una relación de pareja, es decir, libre de violencia y profundo en las emociones que nos mueven día a día y que son parte de nosotros mismos. En particular, el arteterapia integrado al taller de artes fue un gran acierto, pues permitió observar la disciplina artística no como un fin, sino como una herramienta para comunicarnos. El aspecto comunicador es una característica fundamental del arte, pues permite la expresión de forma espontánea (Marxen, 2011).

Durante las últimas sesiones del taller observé positivamente que varios estudiantes tuvieron la confianza y seguridad de compartir aspectos de su vida íntima con el grupo; mencionaron que el espacio lo permitía, pues no había juicios de por medio, más bien apoyo y plena atención.

El taller, además, me permitió conocer sus opiniones sobre los diversos temas planteados, como, por ejemplo, el feminismo, movimiento que ha sido actualmente 
tendencia en redes sociales. Los estudiantes pudieron reflexionar sobre el significado del feminismo y sobre cómo detener la reproducción de mecanismos de discriminación de género.

Por su parte, los varones del grupo fueron conscientes de poseer más privilegios que las mujeres en nuestra cultura. Durante la ejecución del taller ellos escucharon relatos de sus compañeras sobre cómo son juzgadas por su imagen, forma de vestir o comportamiento y esto permitió que empatizaran con ellas, observando que no existe justificación para actuar de forma violenta.

Asimismo, pude confirmar una reacción que ya había observado en mis clases como docente de artes: la poca tolerancia a la frustración al realizar ejercicios visuales. Los estudiantes generalmente se imaginan el resultado y lo ven de forma negativa, piensan que no les quedará bien, que no tienen talento. Esto, a pesar de que desde un principio se les dijo que la expresión, el desarrollo de la creatividad y el proceso de cómo llegaron a realizar sus trabajos visuales, eran más importantes que el resultado final. Observé que incluso tuve que destacar recurrentemente la importancia de aprender a comunicarse a través del lenguaje visual y de atreverse a intentarlo antes de frustrarse por resultados que están insertos en su mente.

En arteterapia se da énfasis a los procesos más que los resultados, ya que estos son los que entregan mayor información del 'yo' interno al momento de realizar las consignas y no su resultado. Este último provoca que los estudiantes se sientan inseguros al realizar y mostrar sus creaciones, pues insisten en otorgar más importancia al carácter estético del trabajo visual.

En futuros talleres, considero que el número de participantes debe seguir reducido (máximo 10), pues logró generar un ambiente acondicionado para que estos se entregaran por completo a los ejercicios de arteterapia, no intimidando a los exponentes a un número mayor de personas. Se generó en los estudiantes una conexión con su yo íntimo y lograron expresarlo a través de recursos del arteterapia, manifestando sus inquietudes con respecto a los estereotipos de género y a la violencia en la pareja.

Finalmente, este taller se seguirá realizando al resto de cursos de enseñanza media (preparatoria) en el mismo establecimiento. En un futuro, espero poder realizarlo en más instituciones de educación con adolescentes, ya que un taller de este tipo es necesario para terminar con la normalización de la violencia.

\section{Referencias Bibliográficas}

Alonso, M. (2004) Arteterapia, mujeres y violencia de género. En Martínez Díez, N. y López Fernández-Cao, M., (coord.), Arteterapia y Educación. Madrid: Consejería de la Educación, C.A.M.

Allen, P. (2010) Arte Terapia, guía de autodescubrimiento a través del arte y la creatividad, España: Editorial Gaia.

Botton, A. \& Armstrong, J. (2017) El arte como terapia. Hong Kong: Editorial Phaidon.

Dalley, T. (1987) El arte como terapia. Barcelona: Herder.

Fontena, C. \& Gatica, A. (s.f.) La Violencia Doméstica hacia el Varón. Recuperado 2 de octubre de 2018 desde: http://www.ubiobio.cl/cps/ponencia/doc/p10.4.htm

Haeussler, I. \& Milicic, N. (s.f.) Confiar en uno mismo: programa de autoestima. Madrid: Editorial Cepe.

Lagarde, M. (2006) Del femicidio al feminicidio. Recuperado 3 de septiembre de 2018 desde: http://www.revistas.unal.edu.co/index.php/jardin/article/view/8343/8987 
Marxen, E. (2011) Diálogos entre arte y terapia. Barcelona: Editorial Gedisa.

Ministerio de la Mujer y la Equidad de Género. (2018) Femicidios. Recuperado 2 de octubre de 2018 desde: https://www.minmujeryeg.cl/sernameg/programas/violencia-contra-lasmujeres/femicidios/

Pololeo Sin Violencia (2017) ¿Qué es la violencia en el pololeo?. Recuperado 28 de agosto de 2018 desde: http://pololeosinviolencia.cl/que-es-la-violencia-en-el-pololeo-2/

Psicología (s.f.) ¿Qué es la Autoestima?. Recuperado 31 de agosto de 2018 desde: https:// www.aulafacil.com/cursos/psicologia/la-autoestima-psicologia/psicologia-que-es-laautoestima-15964

Red Chilena contra la Violencia hacia las Mujeres (2018) Femicidios 2018. Recuperado 20 de septiembre de 2018 desde: https://docs.google.com/spreadsheets/d/1G4AHA5gTppfX 7FCljkTNq3klBn20gA0ci0PReeNKcn4/edit?ts=5a4c51ab\#gid=0

Vizcarra, M. B., Poo, A. M. \& Donoso, T. (2013) Programa educativo para la prevención de la violencia en el noviazgo. Revista de Psicología, 22(1), 48-61. Universidad de Chile, Santiago, Chile.

Zolezzi, A. (2013) Posibilidades del autorretrato fotográfico como herramienta terapéutica en mujeres víctimas de violencia de género: experiencia de un taller. Arteterapia: Papeles de arteterapia y educación artística para la inclusión social, 8, 45-60. 